\title{
THE EVALUATION OF THE AUSTRALIAN OFFICE MARKET
} FORECAST ACCURACY

\begin{tabular}{|r|l|}
\hline Journal: & Journal of Property Investment \& Finance \\
\hline Manuscript ID & JPIF-04-2017-0029.R2 \\
\hline Manuscript Type: & Academic Paper \\
\hline Keywords: & $\begin{array}{l}\text { Australian office market, Causal relationship, Forecast accuracy, Outliers, } \\
\text { Scale-independent forecast accuracy metrics, Forecast errors }\end{array}$ \\
\hline \multicolumn{2}{|c}{} \\
\hline
\end{tabular}

\section{SCHOLARONE ${ }^{\text {m }}$ \\ Manuscripts}




\title{
THE EVALUATION OF THE AUSTRALIAN OFFICE MARKET FORECAST ACCURACY
}

\begin{abstract}
Purpose: Property market models have the overriding aim of predicting reasonable estimates of key dependent variables (demand, supply, rent, yield, vacancy and net absorption rate). These can be based on independent drivers of core property and economic activities. Accurate predictions can only be conducted when ample quantitative data are available with fewer uncertainties. However, a broad-fronted social, technical and ecological evolution can throw up sudden, unexpected shocks that result in the econometric outputs sceptical to unknown risk factors. Therefore, this paper aims at evaluating Australian office market forecast accuracy and to determine whether the forecasts capture extreme downside risk events.
\end{abstract}

Design/methodology/approach: This study follows a quantitative research approach, using secondary data analysis to test the accuracy of economists' forecasts. The forecast accuracy evaluation encompasses the measurement of economic and property forecasts under the following phases: (i) testing for the forecast accuracy, (ii) analysing outliers of forecast errors and (iii) testing of causal relationships. Forecast accuracy measurement incorporates scale independent metrics that include Theil's U values (U1 and U2) and mean absolute scaled error (MASE). Inter Quartile Range (IQR) rule is used for the outlier analysis. To find the causal relationships among variables, the time series regression methodology is utilised, including multiple regression analysis and Granger causality developed under the vector auto regression (VAR).

Findings: The credibility of economic and property forecasts was questionable around the period of the Global Financial Crisis (GFC); a significant man-made Black Swan event. The forecast accuracy measurement highlighted rental movement and net absorption forecast errors as the critical inaccurate predictions. These key property variables are explained by historic information and independent economic variables. However, these do not explain the changes when error time series of the variables were concerned. According to VAR estimates, all property variables have a significant causality derived from the lagged values of Australian S\&P/ASX 200 (ASX) forecast errors. Therefore, lagged ASX forecast errors could be used as a warning signal to adjust property forecasts.

Research Limitations: Secondary data were obtained from the premier Australian property markets: Canberra, Sydney, Brisbane, Adelaide, Melbourne and Perth. A limited 10-year timeframe $(2001$ - 2011) was used in the ex-post analysis for the comparison of economic and property variables. Forecasts ceased from 2011, due to the discontinuity of the Australian Financial Review (AFR) quarterly survey of economists; the main source of economic forecast data.

Practical implications: The research strongly recommended naïve forecasts for the property variables, as an input determinant in each office market forecast equation. Further, lagged forecast errors in the ASX could be used as a warning signal for the successive property forecast errors. Hence, data adjustments can be made to ensure the accuracy of the Australian office market forecasts.

Originality/value: The paper highlights the critical inaccuracy of the Australian office market forecasts around the GFC. In an environment of increasing incidence of unknown events, these types of risk events should not be dismissed as statistical outliers in real estate modelling. As a 
proactive strategy to improve office market forecasts, lagged ASX forecast errors could be used as a warning signal. This causality was mirrored in rental movements and total vacancy forecast errors. The close interdependency between rents and vacancy rates in the forecasting process and the volatility in rental cash flows reflects on direct property investment and subsequently on the ASX, is therefore justified.

Keywords: Australian office market, causal relationship, forecast accuracy, forecast errors, outliers, scale-independent forecast accuracy metrics.

\section{INTRODUCTION}

The Australian property market is characterised by high-high international investment performance quality, granularity, frequency and geographical spread of performance measurements- coupled with high standards of valuation methods and accurate market information with long data time-series (Jones Lang LaSalle [JLL], 2016). This leads to the Australian property market being ranked as the second highly transparent property market globally, behind the UK, in the global real estate transparency index 2016 (JLL, 2016); a major factor in the strong demand for Australian real estate assets from global investors.

The commercial property market is generally divided into broad sectors related to its employment streams (office, industrial and retail), while REITs, pension funds, life insurance companies and foreign investors are the major institutional investors. The office market primarily applies to space created for service jobs, such as business and professional services, administrative and government activity. Some of the nodes of business and community activities are particularly effective in attracting the office market, such as the central business district (CBD) and shopping centres, and non-office nodes like universities, hospitals and airports (Ball, Lizieri, and MacGregor, 1998; McMahan, 2006).

Compared to alternative asset classes, risk of default in the real estate investments holds considerable uncertainty for investors, reflecting numerous investment decisions throughout the life cycle of the property. It is critical that analysts and institutions employ wide-ranged techniques to model and forecast future performance of real estate assets. Property studies are generally based on standard assumptions of mainstream economics: stable preferences are acting in a perfect market, accessible information, and homogenous products that derived from historical data. However, a broad-fronted social, technical, and ecological evolution can throw up sudden, unexpected shocks that result in a possibility of regression from Known back to unknown (Ball et al., 1998; Bardhan and Edelstein, 2010).

This paper aims at evaluating Australian office market forecast accuracy, and to determine whether the forecasts capture extreme downside risk events. The forecast accuracy evaluation encompasses the measurement of economic and property forecasts under the following phases:

(i) Testing for the forecast accuracy

(ii) Analysing outliers of forecast errors

(iii) Testing of causal relationships

These tri-phases are not mutually exclusive; precedent results are supportive to the subsequent steps of understanding the overall picture of the current forecast accuracy. The structure of this paper begins with a review of literature, which includes commercial property market forecasting and forecast accuracy. The next section presents the research methodology followed by data analysis. The last section provides the concluding remarks. 


\section{LITERATURE REVIEW}

\subsection{Commercial property market forecasting}

Real estate assets are characterised by lumpiness and illiquidity involving high unit cost that make decisions irreversible. In Australia, it is significant that direct commercial property investment transaction volumes amounts to approximately $8 \%$ of GDP (JLL, 2016). As real estate forms a major part of the mixed asset portfolio, it is critical that analysts and institutions employ a wide range of techniques for forecasting the performance of real estate assets. The intuitive idea of forecasting is as a structured way of envisioning the future using all available information, prior knowledge on economic relationships. The demand for investment forecast stems from a need to form an educated view of the future before decision making. However, it does not eliminate risk. Rather, forecasting identifies and ranks these risks to assess the likelihood of alternative scenarios to quantify the impact of possible courses of action (Armstrong, 2001; Carnot, Koen, and Tissot, 2005).

Property market models have the overriding aim of predicting reasonable estimates of key dependent variables: demand, supply, rent, returns, yield, vacancy, and cashflows based on information at hand (Brooks and Tsolacos, 2000, 2001, 2003; Chaplin, 1998, 1999, 2000; Matysiak and Tsolacos, 2003). The changes of these variables can be quantified by the internal and the external determinants within which the decisions are made in the market (Higgins, 2000). The interlinked commercial property markets set out economic relationships that are most relevant to the forecasting models. Property market models also need to incorporate behavioural theories of investor expectations. Property market decisions simply based on the current values of important variables, assuming such key variables remain constant in the future, would be termed as 'naïve expectations'. This is an unrealistic short-sighted expectation, particularly in property markets with the experience of sharp changes. Therefore, 'rational expectations' are preferred, whereby versatile knowledge of the property market, the wider economy and the best available theories formulate the future (Ball et al., 1998).

The forecasting methods are primarily based on quantitative and/or qualitative methodologies. Quantitative methods are divided into univariate and multivariate which uses past patterns and past relationships respectively. The main quantitative approaches include exponential smoothing, single-equation regression, simultaneous equation regression, Autoregressive Integrated Moving Average (ARIMA) and Vector auto regression (VAR). Whereas, judgemental methods are based exclusively upon the forecaster's judgement, intuition, or experience to make long-run predictions without using any explicit model. Nowadays, there is an increasing amount of integration between judgmental and statistical procedures (Armstrong, 2001; Carnot et al., 2005).

\subsection{Forecast accuracy measurement}

A higher degree of accuracy does not mean that the forecast is absolutely correct, rather that the risk of error is limited. According to Carnot et al. (2005), Brooks and Tsolacos (2010), forecast errors can have many causes: mismeasurement of problems, misspecification of the model that include statistical complications, decisions or reactions and biases related to the forecasters' behaviour, unforeseeable shocks and structural events. According to Newell and MacFarlane (2006), uncertainty, disagreement, conservative forecasting and inertia have led to serious issues and concerns regarding the accuracy of commercial property forecasting. Forecast errors due to behavioural biases have been addressed by many researchers (Carnot et al., 2005; Gell, 2012). For instance, people may tend to be overly optimistic about their knowledge and tend to overrate small probabilities and underrate larger probabilities of negative events. They may also display excessively conservative behaviours (Geltner and De Neufville, 2015). 
Accuracy is often measured via the size of past errors. Errors are defined as the difference between forecasted and actual realised values. This is shown in equation 1 , where $E_{t}, Y_{t}$ and $X_{t}$ represent the error, forecasted and actual realised values at period $t$ respectively.

$$
\mathbf{E}_{\mathbf{t}}=\mathbf{Y}_{\mathbf{t}}-\mathbf{X}_{\mathbf{t}}
$$

Equation 1: Summary Statistics Describing Past Errors

The statistical properties of $E_{t}$ over the period can be described by two methodologies: scaledependent and scale-independent metrics. Scale-dependent metrics include mean error (ME), mean absolute error (MAE), mean absolute percentage error (MAPE), mean square error (MSE) and root mean square error (RMSE) (Brooks and Tsolacos, 2010; Carnot et al., 2005). The geometric mean absolute error (GMAE) has also been suggested, as opposed to the arithmetic mean which uses a simple sum of absolute errors. GMAE is defined as the $\mathrm{n}^{\text {th }}$ root of the product of $n$ numbers and is a more accurate representation of the average. The use of absolute or squared values of the forecast errors, prevent positive and negative errors from offsetting each other. For assessing the forecast accuracy on a single series, MAE is preferred because it is easiest to understand and compute, however they are not meaningful for assessing the accuracy across multiple series. Therefore, a variant is often reported in MAPE. However, if there are zero values in the series, MAPE has a disadvantage of being infinite or undefined (Carnot et al., 2005; Hyndman, 2006).

A drawback of the above scale-dependent measures is that they cannot be readily compared across variables to determine which is more accurately presented. One way to overcome this problem is to normalise the values, which involves dividing them by a statistic describing how large the values of the variables are (Carnot et al., 2005; Hyndman, 2006). Alternatively, scaleindependent measurements such as Theil's U1 and U2 coefficients and mean absolute scaled error (MASE) involves benchmarking against naïve forecast error (NFE). Naïve Forecast (NF) assumes that the following year's outcome can be predicted by the current year's outcome (Naïve 1). As an alternative, the second naïve comparison forecast uses the long-term average up to the date of the forecast (Naïve 2). Matysiak, Papastamos, and Stevenson (2012) made a comparison in between both naïve assumptions (1 and 2) when reassessing the accuracy of UK commercial property forecasts. In the majority of cases, the Naïve 2 assumption, the long-term average figure, tended to do a better job than the Naïve 1 last year's value. Yet, for the current analysis, the researchers have used Naïve 1, the last observed value, allowing the market volatility due consideration instead of using long term averages. Theil's U1, U2 and MASE equations are given in equation 2 and 3 respectively.

$$
\mathrm{U} 1=\frac{\sqrt{\mathrm{MSE}}}{\sqrt{\frac{\sum_{\mathrm{t}=1}^{\mathrm{T}} \mathbf{X}_{\mathrm{t}}^{2}}{n}}+\sqrt{\frac{\sum_{\mathrm{t}=1}^{\mathrm{T}} \mathrm{Y}_{\mathrm{t}}^{2}}{n}}}
$$$$
\mathbf{U} 2=\frac{\sqrt{\sum_{t=1}^{\mathbf{T}}\left(\frac{\left(\mathbf{Y}_{t}-\mathbf{X}_{t}\right)^{2}}{\mathbf{T}}\right)}}{\sqrt{\sum_{t=1}^{\mathbf{T}}\left(\frac{\left(\mathbf{X}_{(t-1)}-\mathbf{X}_{t}\right)^{2}}{T}\right)}}=\frac{\sqrt{M S E}}{\sqrt{M S E^{\text {naive }}}}
$$

Equation 2: Theil's U Coefficients

$$
\operatorname{MASE}=\operatorname{mean}\left\{\left|\frac{\mathbf{e}_{\mathbf{t}}}{\left|\frac{1}{n-1} \sum_{i=2}^{n}\right| X_{i}-X_{i-1} \mid}\right|\right\}
$$

Equation 3: Mean Absolute Scaled Error 
MASE method involves scaling the errors based on the in-sample MAE from the naïve forecast method. The denominator of MASE is the MAE of the naïve method. The only circumstance when MAE would be undefined is when all the historical observations are equal. The only difference between U2 and MASE is the use of the square root in U2. Whereas, the denominator of $\mathrm{U} 1$ restricts the variations of the coefficient between zero and one. The closer these three measurements arrived at zero are the better the prediction (Brooks and Tsolacos, 2010; Carnot et al., 2005). Theil's U-statistic has been widely used in benchmarking commercial property forecasting ability (Newell and MacFarlane, 2006).

An important task for property analysts is the application of various methodologies to identify the best performing models that provide better forecasts. However, this task requires time and knowledge to apply various methodologies in different scenarios. Supplementary, the characteristics of the data (for example, strongly trended, non-trended) can also determine the extent to which various methodologies can be used (Brooks and Tsolacos, 2010; Matysiak and Tsolacos, 2003). There have been several scholarly efforts in determining the outperforming models based on the aforementioned accuracy measures. For instance, the regression equation is better than exponential smoothing, error correction model and naïve technique (D'Arcy, McGough, and Tsolacos, 1999; McGough, Tsolacos, and Olli, 2000); ARIMAX outperforms regression equations (Karakozova, 2004); Bayesian VAR is over ARIMA, single equation and simultaneous equation regression (Stevenson and McGarth, 2003). Irrespective of the fact, it must be noted that all these techniques have their own pros and cons and would be used for various situations. For example, error correction models would be used when one has good reasons to believe that the time series contains a unit root. Also, it is useful if one is trying to determine how quickly the time series reverts to a long run mean following a shock. However, regression (for example, pooled Ordinary LeaseLeast Squares) might be useful if dealing with a simple cross section of data.

\section{METHODOLOGY}

The current research study follows a quantitative research approach to answer the research objective to test the accuracy of economists' forecasts to determine whether they capture extreme downside risks. The status of economic and property forecast accuracy were analysed under the following facets: testing for the forecast accuracy, analysing outliers of forecast errors and testing for relationships.

\subsection{Data collection}

Australian commercial property market data and macro-economic data, including both actual and forecast data, were collected for a 10-year period (2001-2011) capturing the GFC effects. The time boundary considered in this study limits the comparison between economic and property variables after 2011 due to the discontinuation of the main source of economic forecast data; the Australian Financial Review (AFR) Quarterly Survey of Economists. The purpose of collecting economic variables is to triangulate the empirical results with the literature findings.

Economic data comprises the Australian Cash Rate (CR), Australian 10-year Bond Rate (BR), \$AUD/\$USD (FX) and Australian S\&P/ASX 200 (ASX). Further, the RBA tends to adjust the cash rate driven by inflation. Therefore, the effects of inflation are captured in the cash rate, and the cash rate could be a proxy for inflation. Also, it must be noted that the GDP growth rate follows a slow-moving trend, therefore when prioritising the independent variables, GDP can be set aside from the modelling. Property variables are rental movement-prime (RMP), rental movement-secondary (RMS), yield-prime (YP), yield-secondary (YS) direct vacancy rate (DV), total vacancy rate (TV) and net absorption rate-6 months (NA6) across Australian Central Business District (CBD) office markets: Canberra Civic, Sydney, Brisbane, Adelaide Core, 
Melbourne, and Perth. Hobart CBD and Darwin CBD were excluded from the analysis due to their relatively lesser total stock, as per office market report - July 2011 produced by the Property Council of Australia (PCA). The researchers took a weighted average of six key CBDs to arrive at the broader view of the Australian market. The weights are taken as a percentage to the total stock $\left(\mathrm{m}^{2}\right)$ excluding Hobart and Darwin

The economic forecast data were obtained from the Quarterly Survey of Economists conducted by the Australian Financial Review. The actual economic data for the selected variables were obtained from the Australian Bureau of Statistics (ABS), Reserve Bank of Australia (RBA), World Bank and Yahoo Finance. Property forecast data for 6 months-out forecast horizon was obtained from the Australian office market report produced quarterly by PCA. Property economists across the country have contributed their individual predictions in each periodic report. Subsequently, the researcher has taken the simple average of all the individual forecasts for the successive quantitative analysis. Whereas the property data were obtained from PCA, CBRE global research gateway and Savills Australia. All the above-mentioned data are commercially available.

\subsection{Data analysis}

Scale-free metrics were used for the accuracy measurements, including MASE and Theil's U inequality coefficient (U1 and U2). Thus, they can be readily compared against various property and economic variables. The validity of the results was ensured by normality test. According to Makridakis, Hogarth, and Gaba (2009), for the model to be statistically accurate, its forecast errors must follow a normal distribution.

The analysis is extended in identifying statistical outliers in the error distributions. In other words, the intention is to find random large errors outside the realm of regular expectations. Inter Quartile Range (IQR) rule for outliers is used for this part of the analysis. The data points between the values for Q1 $-1.5 \times \mathrm{IQR}$ and Q3 + $1.5 \times \mathrm{IQR}$ are the reasonable values, while the outliers mark outside those fences.

The final analysis tests for relationships between economic and property variables based on two methodologies: multiple regression and vector auto regression (VAR). The application regression methodologies assume that the analysed signals are stationary. If the variables are non-stationary, the test is done using first differences to avoid spurious regression. While testing all the economic and property time series, some appeared to be stationary in their original form (in level). Irrespective of this fact, the researcher has generated $1^{\text {st }}$ difference time series for all the different economic and property variables, so these variables are presented in growth rates.

VAR analysis is used to evaluate the dependent variable based on its own lags and those of the independent variables. That enables capture of the linear interdependencies among multiple time series (Carnot et al., 2005; Gujarati and Porter, 2009). Equation 4 explains how a VAR is estimated, assume Y1 and Y2 variables are having bilateral causality and each equation contains $\mathrm{k}$ lag values of $\mathrm{Y} 1$ and $\mathrm{Y} 2$. Instead of having only two variables, the system could include number variables such as $\mathrm{Y} 1_{\mathrm{t}}, \mathrm{Y} 2_{\mathrm{t}} \ldots \ldots \mathrm{Y}_{\mathrm{nt}}$ and each of which has an equation.

$$
\begin{aligned}
& \mathrm{Y} 1_{\mathrm{t}}=\mathrm{c}+\sum_{\mathrm{i}=1}^{\mathrm{k}} \beta 1_{\mathrm{i}} \mathrm{Y} 1_{\mathrm{t}-\mathrm{i}}+\sum_{\mathrm{i}=1}^{\mathrm{k}} \alpha 1_{\mathrm{i}} \mathrm{Y} 2_{\mathrm{t}-\mathrm{i}}+\varepsilon_{\mathrm{t}} \\
& \mathrm{Y} 2_{\mathrm{t}}=\mathrm{c}^{\prime}+\sum_{\mathrm{i}=1}^{\mathrm{k}} \beta 2_{\mathrm{i}} \mathrm{Y} 1_{\mathrm{t}-\mathrm{i}}+\sum_{\mathrm{i}=1}^{\mathrm{k}} \alpha 2_{\mathrm{i}} \mathrm{Y} 2_{\mathrm{t}-\mathrm{i}}+\varepsilon_{\mathrm{t}}^{\prime}
\end{aligned}
$$

Equation 4: Vector Autoregressive Model 
Subsequently, the Granger causality is developed under VAR environment. Granger causality seeks to answer how much of the current $\mathrm{Y}$ can be explained by past values of $\mathrm{Y}$ and then analyse whether adding lagged values of $\mathrm{X}$ can improve the explanation. $\mathrm{Y}$ is said to be Grangercaused by $\mathrm{X}$ if $\mathrm{X}$ is a determinant of $\mathrm{Y}$, or equivalently, if the coefficients on the lagged $\mathrm{X}$ 's are statistically significant. Further, two-way causation also could be resulted where $\mathrm{X}$ Granger causes Y and Y Granger causes X (Granger, 1969).

\section{EVALUATION OF PROPERTY FORECAST ACCURACY}

\subsection{Scale-invariant Forecast Accuracy Measurement}

Figure 1 summarises scale-independent statistical results, including MASE and Theil's U1 and U2 coefficients, of all economic and property variables at the country level to enable comparison. Theil's U1 coefficient revealed that forecast errors are negligible for the cash rate, bond rate and \$AUD/\$USD as economic variables, and for property yields. The focus must be on rental movement and net absorption - 6 months forecast errors - as they are the critical inaccurate predictions.

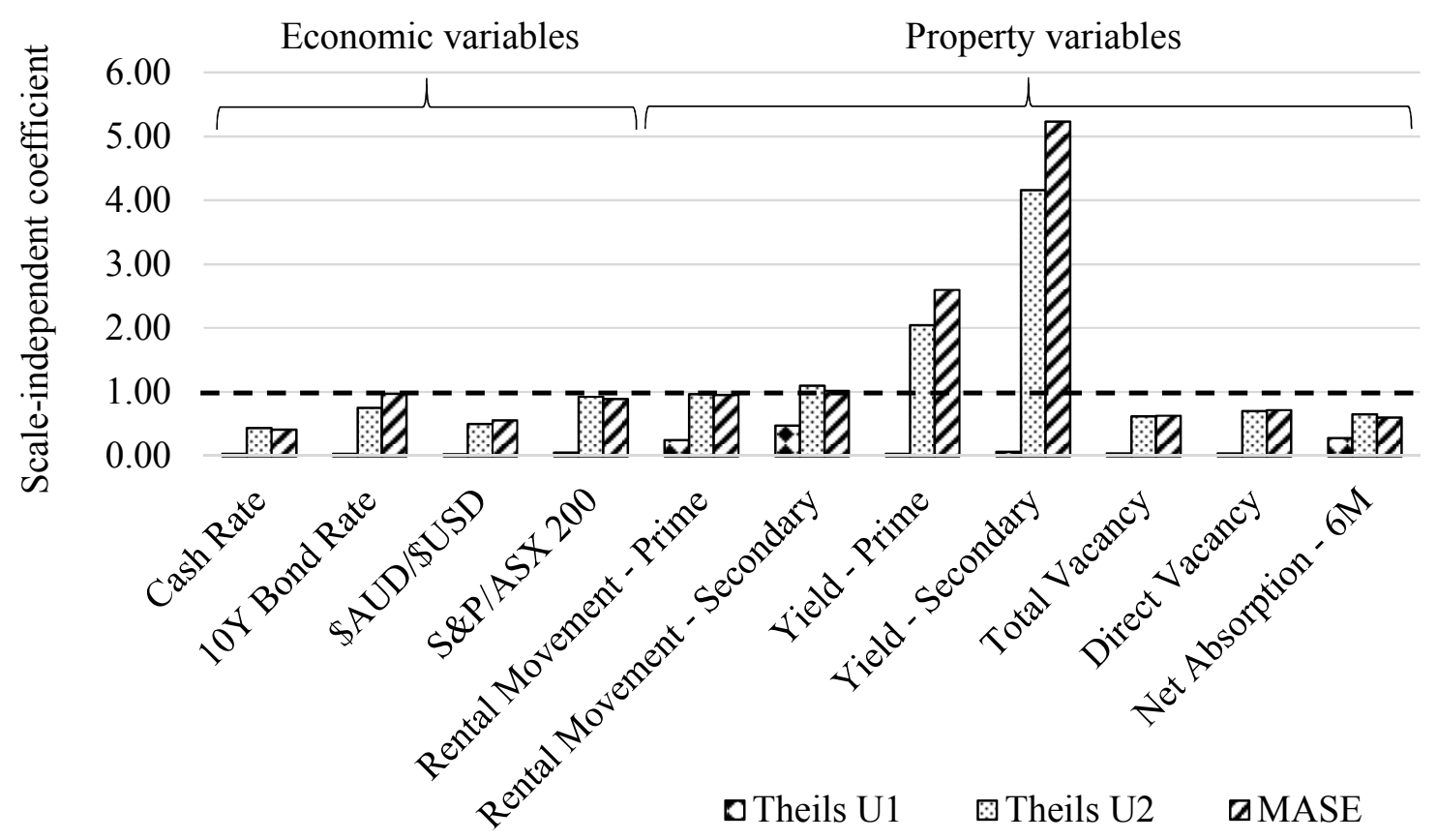

Figure 1: The Comparison of Economic and Property Forecast Accuracy

Though yield forecast errors are minimal as per U1, naïve forecast errors (NFE) are smaller, which reflected higher coefficient above one for MASE and U2. Further, there is no clear distinction between naïve forecasts (NF) and economists' forecasts for rental movements. Similarly, a study conducted by Newell and MacFarlane (2006) in Australia for the period 19992005, pointed out that the naïve forecasting strategies for CBD office and non-CBD office property has outperformed forecasters. Therefore, naïve assumption must be incorporated as a key input variable in property forecasting. And as compared with economic forecasts, the property forecasts are not at the standard of economic forecasts as revealed by scaledindependent measures.

These results were validated by the normality test. Normality tests are associated with the null hypothesis that the population from which a sample is extracted follows a normal distribution. 
The Shapiro-Wilk test, Anderson-Darling test, Lilliefors test and Jarque-Bera used to test the normality. Test results given in Table 1 revealed the statistical inaccuracy of rental movements and net absorption forecast models.

Table 1: The Normality Test Output

\begin{tabular}{|c|c|c|c|c|}
\hline Variable $\backslash T e s t$ & Shapiro-Wilk & Anderson-Darling & Lilliefors & Jarque-Bera \\
\hline Yield - Prime $^{*}$ & 0.271 & 0.177 & 0.182 & 0.361 \\
\hline Rental Movement - Prime & 0.020 & 0.004 & 0.026 & 0.363 \\
\hline Total Vacancy $^{*}$ & 0.531 & 0.386 & 0.476 & 0.852 \\
\hline $\begin{array}{l}\text { Net absorption }-6 \mathrm{~m} \\
{ }^{*} \text { statistically accurate mode }\end{array}$ & $<0.0001$ & $<0.0001$ & $<0.0001$ & $<0.0001$ \\
\hline
\end{tabular}

\subsection{Inter-quartile rule for forecast error outliers}

Table 2 summarises IQR analysis for outliers at the country level to compare against different economic and property variables. In order to avoid the scale dependency, errors are given as a percentage of actual. Q1 $-1.5 \times \mathrm{IQR}$ and Q3 $+1.5 \times \mathrm{IQR}$ fences abbreviated as $-\mathrm{F}$ and $+\mathrm{F}$ in the Table 2.

Table 2: IQR Rule for Economic and Property Outliers Given in Error Percentage

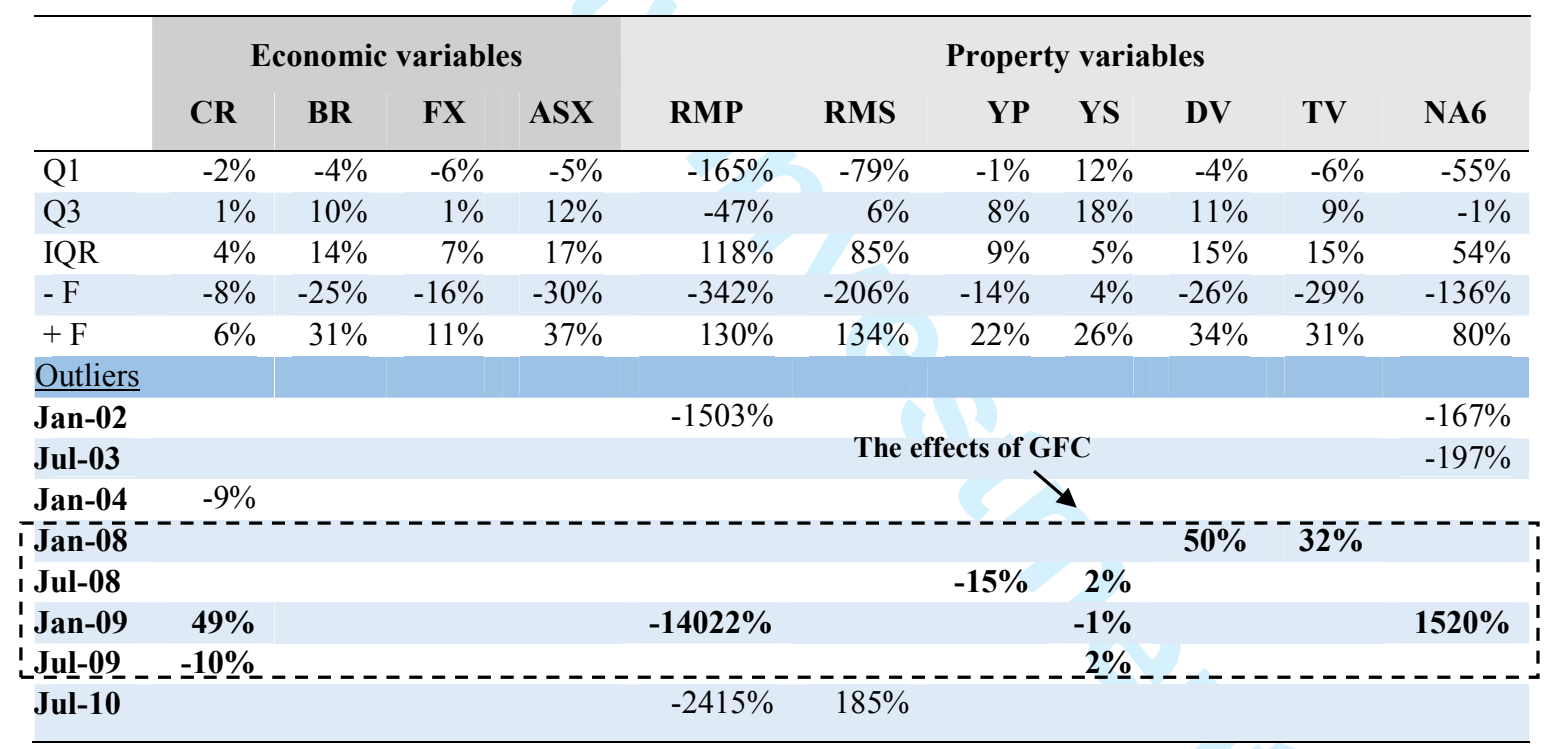

In emphasis, the credibility of rental movement-prime (RMP) forecasts have been diminished by having extremely large errors specified in percentage of actual. January 2009 was identified as a worst-case scenario with a very high over-estimation of forecasts, where forecast was $9.93 \%$ with an actual movement of $-0.07 \%$. Further, secondary rental movement (RMS) and net absorption (NA6) forecast errors also could be highlighted. Similarly, as per Matysiak et al. (2012), the worst forecasting periods for the one-year-ahead forecasts and two-year-ahead forecasts in UK property market for the rental growth case were year 2010 and 2009 respectively. Figure 2 demonstrates the magnitude of percentage error for all the property variables in total over the period from January 2001 to January 2012. 


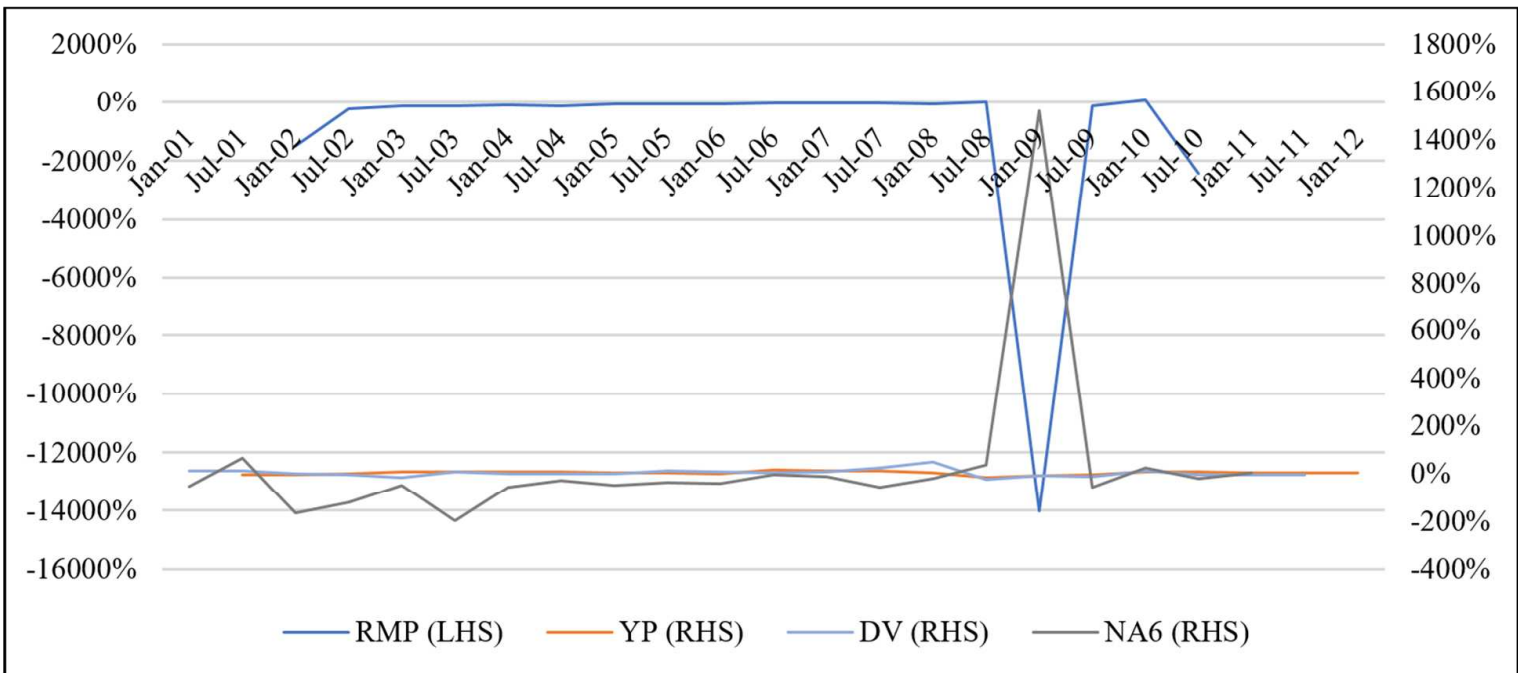

Figure 2: Line Diagram for Property Forecasts Errors in Percentages

Since rental movement forecast errors are critical as evidenced in the preceding analysis, the line diagram is illustrated with two y-axes, taking out rental movement to one y axis (LHS) and the other variables in the other y-axis (RHS) as shown. The timeframe around 2008-2009 has witnessed a significant inaccuracy of property forecasts. These errors are subject to both under and over-estimation of forecasts as shown by volatility spread across positive and negative values. The effects of the Global Financial Crisis (GFC) may lead to this swing in the forecast inaccuracy. Further, it can be stressed that there is another spike around the GFC caused by net absorption (NA6) forecast errors. Anyway, that is not as critical as rental growth, but required attention.

\subsection{Testing for relationships between economic and property variables}

As discussed in the literature review, macroeconomic factors have been the driving forces in modelling and forecasting real estate performance. Further, sub-section 4.2 recommends naïve assumption to be incorporated as a key input variable in the forecasting. This part of the analysis is dealt with answering the following sub-questions.

(i) Do economic forecasts drive property forecasts in the real practice as per the theoretical underpinning?

(ii) If (i) is true, can property forecast errors be explained by economic forecast errors?

Therefore, the intention of this section is not to form linear regression models, but to find any significant explanation of the property variables by economic variables and the property variable's own historic information. Regression output is reproduced in Table 3. Attention should be given to multiple $R, R$ squared, significance $F$, and p-value. ' $D$ ' represents that the variable is given in its $1^{\text {st }}$ difference and ' $A$ ' represents the actual value of the variable.

Table 3: Multiple Regression for Forecasts: Property Vs Economic

\begin{tabular}{lrcrr}
\hline Regression Statistics & RMP_D & YP_D & TV_D & NA6_D \\
\hline Multiple R & $\mathbf{0 . 8 6}$ & $\mathbf{0 . 7 7}$ & $\mathbf{0 . 9 5}$ & $\mathbf{0 . 6 9}$ \\
R Squared & $\mathbf{0 . 7 4}$ & $\mathbf{0 . 6 0}$ & $\mathbf{0 . 9 0}$ & 0.47 \\
Adjusted R Square & $\mathbf{0 . 6 2}$ & 0.46 & $\mathbf{0 . 8 6}$ & 0.27 \\
Sig. F & $\mathbf{0 . 0 1}$ & $\mathbf{0 . 0 2}$ & $\mathbf{0 . 0 0}$ & $\mathbf{0 . 1 0}$ \\
\hline
\end{tabular}




\begin{tabular}{lcccc}
\hline Regression Statistics & RMP_D & YP_D & TV_D & NA6_D \\
\hline p-value & $\mathbf{0 . 0 5}$ & & \\
RMP_NF_D [i.e. RMP_A_D in Lag1] & & $\mathbf{0 . 0 6}$ & \\
YP_NF_D [i.e. YP_A_D in Lag1] & & & $\mathbf{0 . 0 0}$ & \\
TV_NF_D [i.e. TV_A_D in Lag1] & & & & \\
NA6_NF_D [i.e. NA6_A_D in Lag1] & $\mathbf{0 . 0 4}$ & 0.16 & $\mathbf{0 . 0 0}$ & 0.17 \\
CR_F_D & 0.30 & 0.86 & 0.20 & 0.38 \\
BR_F_D & $\mathbf{0 . 0 6}$ & 0.99 & $\mathbf{0 . 0 1}$ & 0.17 \\
FX_F_D & 0.52 & 0.47 & $\mathbf{0 . 0 6}$ & $\mathbf{0 . 1 0}$ \\
ASX_F_D & & &
\end{tabular}

Note: Bold and Italic figures indicate statistical significance

The conclusive evidence in this part of the analysis shows that the key property variables have a strong coefficient correlation, given in multiple $\mathrm{R}$, with its own historic information and independent economic variables. Further, as an overall output between variables give a statistically significant $\mathrm{p}$-value for $\mathrm{F}$-statistic while individual independent variables have contributed to this overall significance. However, the scope of this regression analysis is limited to economic vs. property forecasts, while interdependencies among property variables have not been re-tested.

The analysis is further extended to understand any significant explanation between economic and property variables when error time series is concerned. The test results are tabulated in Table 4 below. However, none of the regression statistics provide a strong relationship or a better explanation through independent variables.

Table 4: Multiple Regression for Forecast Errors: Property Vs Economic

\begin{tabular}{lrrrr}
\hline Regression Statistics & RMP_FE_D & YP_FE_D & TV_FE_D & NA6_FE_D \\
\hline Multiple R & 0.59 & 0.37 & 0.24 & 0.42 \\
R Square & 0.35 & 0.14 & 0.06 & 0.17 \\
Adjusted R Square & 0.13 & -0.09 & -0.19 & -0.06 \\
Sig. F & 0.24 & 0.67 & 0.92 & 0.58 \\
\hline p-value & & & & \\
$\quad$ CR_FE_D & 0.07 & 0.22 & 0.66 & 0.94 \\
$\quad$ BR_FE_D & 0.15 & 0.20 & 0.44 & 0.91 \\
$\quad$ FX_FE_D & 0.66 & 0.21 & 0.44 & 0.20 \\
$\quad$ ASX_FE_D & 0.63 & 0.77 & 0.78 & 0.73 \\
\hline
\end{tabular}

Since property forecast errors cannot be explained by economic forecast errors as per the multiple regression analysis, the next part of the analysis adopts a one step forward using lagged values for independent variables adhering the Vector Auto Regression (VAR) methodology. VAR provides a linear interdependency among multiple time series, which superficially resembles simultaneous-equations modelling considering several endogenous variables together. Each endogenous variable is explained by its own lagged values and the lagged values of other endogenous variables in the model (Carnot et al., 2005; Gujarati and Porter, 2009). A theoretical overview of VAR was discussed in the methodology section.

One of the requirements of a VAR is that the variables must be all be I (0), that means to have the same order of integration and not be cointegrated. Since the variable set in this study is nonstationary at level, all the variables are converted to a stationary after performing the Augmented 
Dickey Fuller test on differenced series. Then, all the variables must be tested for cointegration. Depending on the cointegration test results, the application of the model is either Vector error correction model (VECM) /restricted VAR or unrestricted VAR. VECM is used if the variables are cointegrated and VAR is used if the variables are not cointegrated. However, there is a limitation of having insufficient data to perform Johansen Cointegration test. Hence, the computation is carried forward with unrestricted VAR with an underlying assumption of the same order of integration in variables.

The next important point in VAR estimation is to determine the number of lags to use in the model. The two most common selection criteria are the Akaike Information Criterion (AIC) and the Schwarz's Bayesian Information Criterion (SIC/BIC/SBIC). However, 10 years bi-annual data series is insufficient to form more than one lag for this testing. Literally in this study, one lag means to use six months before values. Hence, it could be irrational if the researcher considered values of 12 months ago, and more ( 2 lags and more). Therefore, only one lag is used for the VAR and for subsequent Granger causality testing. Table 5, 6, 7 and 8 tabulate the summary of the Granger causality results. The Granger causality test is associated with the null hypothesis that the lagged independent variables cause the dependent variable. P-values less than $0.1,0.05$ and 0.01 indicate statistical significance at the $10 \%, 5 \%$ and $1 \%$ level of significance respectively. If the lagged values of the independent economic variable/s cause dependent property variable by rejecting the null hypothesis, then it will check whether there is any bidirectional causality. That is, whether the lagged values of property variable can cause the economic variable/s. The test output is followed by a brief explanation where $\mathrm{X} \Rightarrow^{\mathbf{G}} \mathrm{Y}$ means "X (lag 1) does Granger-cause Y".

Table 5: Granger Causality between Rental Movement and Economic Forecast Errors

\begin{tabular}{llll} 
Dependent variable: RMP_FE_D & & \\
\hline Excluded & Chi-sq & df & \multicolumn{1}{l}{ Prob. } \\
\hline CR_FE_D & 0.322882 & 1 & 0.5699 \\
BR_FE_D & 0.019033 & 1 & 0.8903 \\
ASX_FE_D & $\mathbf{6 . 0 3 6 5 9 9}$ & $\mathbf{1}$ & $\mathbf{0 . 0 1 4 0}$ \\
FX_FE_D & 0.455341 & 1 & 0.4998 \\
\hline All & 12.25007 & 4 & 0.0156 \\
\hline
\end{tabular}

Dependent variable: ASX_FE_D

\begin{tabular}{llrr}
\hline Excluded & Chi-sq & df & \multicolumn{1}{l}{ Prob. } \\
\hline $\boldsymbol{R M P}$ PFE_D & $\mathbf{4 . 0 0 5 0 7 0}$ & $\mathbf{1}$ & $\mathbf{0 . 0 4 5 4}$ \\
CR_FE_D & 0.246010 & 1 & 0.6199 \\
BR_FE_D & 0.400442 & 1 & 0.5269 \\
FX_FE_D & 4.532049 & 1 & 0.0333 \\
\hline All & 17.19280 & 4 & 0.0018 \\
\hline
\end{tabular}

Conclusion: ASX_FE_D $(\operatorname{lag} 1) \Rightarrow{ }^{\mathrm{G}} \mathrm{RMP} \_$FE_D

$$
\text { RMP_FE_D (lag1) } \Rightarrow^{\mathbf{G}} \text { ASX_FE_D }
$$

Table 6: Granger Causality between Property Yield-prime and Economic Forecast Errors

\begin{tabular}{llll}
\multicolumn{2}{l}{ Dependent variable: YP_FE_D } & & \\
\hline Excluded & Chi-sq & df & \multicolumn{1}{l}{ Prob. } \\
\hline CR_FE_D & 0.079025 & 1 & 0.7786 \\
BR_FE_D & 0.219559 & 1 & 0.6394 \\
ASX_FE_D & $\mathbf{7 . 8 1 4 2 7 7}$ & $\mathbf{1}$ & $\mathbf{0 . 0 0 5 2}$ \\
FX_FE_D & 0.406055 & 1 & 0.5240 \\
\hline All & 10.70876 & 4 & 0.0300 \\
\hline
\end{tabular}

\begin{tabular}{llrl} 
Dependent variable: ASX_FE_D & & \\
\hline Excluded & Chi-sq & df & \multicolumn{1}{l}{ Prob. } \\
\hline YP_FE_D & 0.618430 & 1 & 0.4316 \\
CR_FE_D & 1.174155 & 1 & 0.2785 \\
BR_FE_D & 0.021936 & 1 & 0.8823 \\
FX_FE_D & 0.004398 & 1 & 0.9471 \\
\hline All & 4.638529 & 4 & 0.3264 \\
\hline
\end{tabular}

Conclusion: ASX_FE_D (lag1) $\Rightarrow{ }^{\mathbf{G}} \mathrm{YP} \_$FE_D

$$
\text { However, YP_FE_D }(\operatorname{lag} 1) \nRightarrow^{\mathbf{G}} \text { ASX_FE_D }
$$


Table 7: Granger Causality between Property Total vacancy and Economic Forecast Errors

\begin{tabular}{llll}
\multicolumn{4}{l}{ Dependent variable: TV_FE_D } \\
\hline Excluded & Chi-sq & df & \multicolumn{1}{l}{ Prob. } \\
\hline CR_FE_D & 0.104207 & 1 & 0.7468 \\
BR_FE_D & 0.626829 & 1 & 0.4285 \\
ASX_FE_D & $\mathbf{3 . 0 5 5 9 8 2}$ & $\mathbf{1}$ & $\mathbf{0 . 0 8 0 4}$ \\
FX_FE_D & 0.408578 & 1 & 0.5227 \\
\hline All & 10.63325 & 4 & 0.0310 \\
\hline
\end{tabular}

\begin{tabular}{llrr}
\multicolumn{4}{l}{ Dependent variable: ASX_FE_D } \\
\hline Excluded & Chi-sq & df & \multicolumn{1}{l}{ Prob. } \\
\hline $\boldsymbol{T}$ _FE_D & $\mathbf{4 . 4 0 0 9 8 5}$ & $\mathbf{1}$ & $\mathbf{0 . 2 0 2 0}$ \\
CR_FE_D & 0.292092 & 1 & 0.3004 \\
BR_FE_D & 1.165297 & 1 & 0.2054 \\
FX_FE_D & 1.821414 & 1 & 0.0141 \\
\hline All & 10.37064 & 4 & 0.0936 \\
\hline
\end{tabular}

$\begin{aligned} \text { Conclusion: } & \text { ASX_FE_D (lag1) } \Rightarrow^{\mathbf{G}} \text { TV_FE_D } \\ & \text { TV_FE_D (lag1) } \Rightarrow^{\mathbf{G}} \text { ASX_FE_D }\end{aligned}$

Table 8: Granger Causality between Property Total vacancy and Economic Forecast Errors

Dependent variable: NA6_FE_D

\begin{tabular}{llll}
\hline Excluded & Chi-sq & df & \multicolumn{1}{l}{ Prob. } \\
\hline $\boldsymbol{C} \boldsymbol{R}_{-} \boldsymbol{F E} \boldsymbol{E}_{-} \boldsymbol{D}$ & 4.847444 & $\mathbf{1}$ & $\mathbf{0 . 0 2 7 7}$ \\
\hline $\boldsymbol{B} \boldsymbol{R}_{-} \boldsymbol{F} \boldsymbol{E}_{-} \boldsymbol{D}$ & $\mathbf{6 . 9 7 6 4 4 6}$ & $\mathbf{1}$ & $\mathbf{0 . 0 0 8 3}$ \\
$\boldsymbol{A} \boldsymbol{S} \boldsymbol{X}_{-} \boldsymbol{F E} \_\boldsymbol{D}$ & $\mathbf{1 0 . 9 7 2 9 0}$ & $\mathbf{1}$ & $\mathbf{0 . 0 0 0 9}$ \\
FX_FE_D & 0.088180 & 1 & 0.7665 \\
\hline All & 12.54215 & 4 & 0.0137 \\
\hline
\end{tabular}

Dependent variable: BR_FE_D

\begin{tabular}{llrc}
\hline Excluded & Chi-sq & df & \multicolumn{1}{c}{ Prob. } \\
\hline NA6_FE_D & 0.005301 & 1 & 0.9420 \\
CR_FE_D & 0.571767 & 1 & 0.4496 \\
ASX_FE_D & 0.336734 & 1 & 0.5617 \\
FX_FE_D & 2.436041 & 1 & 0.1186 \\
\hline All & 5.638186 & 4 & 0.2278 \\
\hline
\end{tabular}

\begin{tabular}{|c|c|c|c|}
\hline Excluded & Chi-sq & df & Prob. \\
\hline NA6_FE_D & 1.627957 & 1 & 0.2020 \\
\hline BR_FE_D & 1.072435 & 1 & 0.3004 \\
\hline ASX_FE_D & 1.603881 & 1 & 0.2054 \\
\hline FX_FE_D & 6.020434 & 1 & 0.0141 \\
\hline All & 7.945812 & 4 & 0.0936 \\
\hline
\end{tabular}

\begin{tabular}{llll}
\multicolumn{4}{l}{ Dependent variable: ASX_FE_D } \\
\hline Excluded & Chi-sq & df & Prob. \\
\hline NA6_FE_D & 1.755746 & 1 & 0.1852 \\
CR_FE_D & 1.035291 & 1 & 0.3089 \\
BR_FE_D & 0.141455 & 1 & 0.7068 \\
FX_FE_D & 0.930698 & 1 & 0.3347 \\
\hline All & 9.463609 & 4 & 0.0505 \\
\hline
\end{tabular}

Conclusion: CR_FE_D (lag1) $\Rightarrow^{\mathbf{G}}$ NA6_FE_D

$$
\begin{aligned}
& \text { BR_FE_D (lag1) } \Rightarrow{ }^{\mathbf{G}} \text { NA6_FE_D } \\
& \text { ASX_FE_D (lag1) } \Rightarrow^{\mathbf{G}} \text { NA6_FE_D } \\
& \text { However, YP_FE_D }(\text { lag1 }) \nRightarrow^{\mathbf{G}} \text { CR_FE_D, BR_FE_D and ASX_FE_D }
\end{aligned}
$$

Note: Bold and Italic figures indicate statistical significance

As a key finding, there is a significant causality for all key property forecast errors by Australian S\&P/ASX 200 (ASX) forecast. It could be stated that preceding forecast errors in the Australian S\&P/ASX 200 has a causal effect on the current property forecast error. Therefore, the significant results from this Granger causality test show forecast error in the ASX has been a warning signal to adjust current property forecasts to improve the forecast accuracy.

Furthermore, there is a bi-directional causality where property forecast errors may give a warning sign to economic forecast errors. This causality has mirrored rental movements and total vacancy forecast errors. It can be theoretically justified that there is a close interdependency between rents and vacancy rates in the forecasting process, and the volatility in rental cash flows reflects the direct property investment and subsequently the ASX. The summary of causality between economic and property forecast errors from Granger Causality under the VAR environment can be illustrated in Figure 3. 


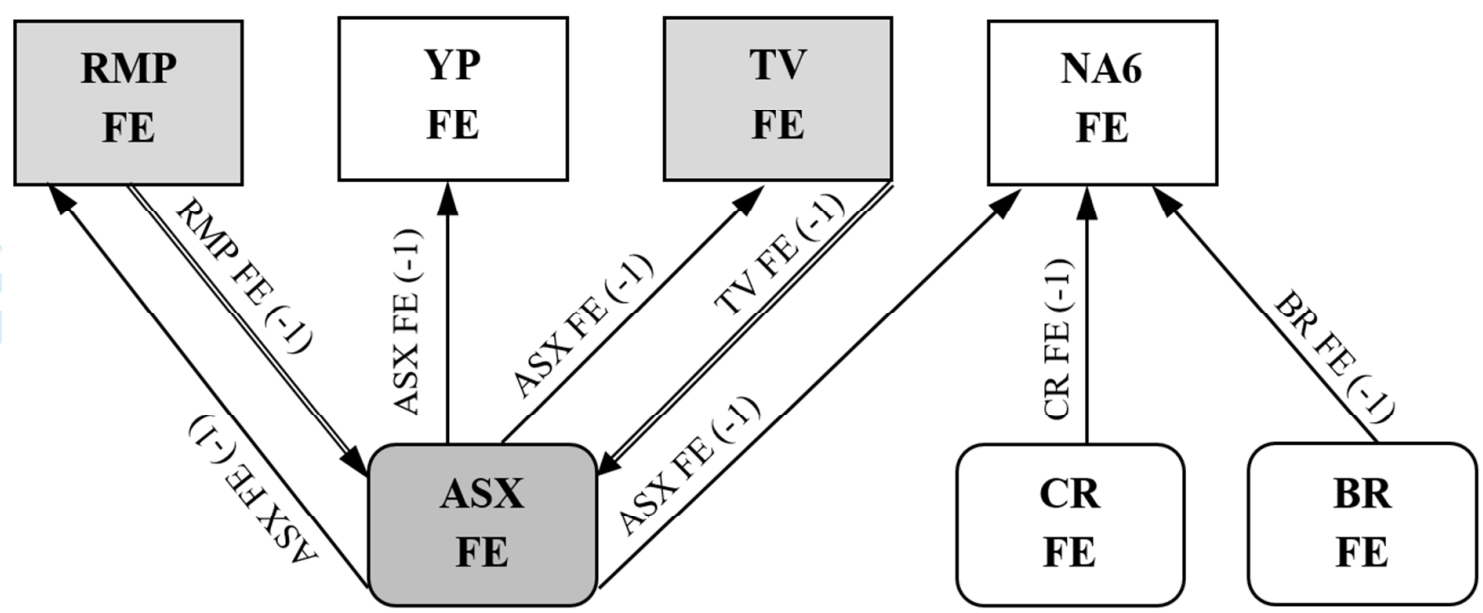

Figure 3: Granger Causality of Property and Economic Forecast Errors

However, as previously noted, the credibility of VAR estimates is limited due to small sample limitation when defining lag lengths and testing for cointegration. To reinstate the reader's confidence in this piece of work, the researcher has given the following Pearson correlation matrix (Table 9) between property forecast errors, with its own lagged values and the lagged values of economic forecast errors. The output revealed no correlation between the variables when the original forecast error series is concerned, which is similar to the multiple regression output for forecast errors shown in Table 4.

Yet, there is a significant correlation between property forecast errors, with the preceding period's S\&P/ASX 200 (with $1 \mathrm{lag}$ ) at the $95 \%$ level of significance when aligned with the VAR estimates discussed along with the Granger causality. Additionally, total vacancy forecast errors correlate with its own lagged values along with the lagged bond rate forecast errors at $95 \%$ confidence level.

Table 9: Correlation Matrix of Key Property and Economic Forecast Errors

\begin{tabular}{|c|c|c|c|c|c|}
\hline & & RMP_FE_D & YP_FE_D & TV_FE_D & NA6_FE_D \\
\hline RMP_FE_D (-1) & $\begin{array}{l}\text { Pearson Correlation } \\
\text { Sig. (2-tailed) }\end{array}$ & $\begin{array}{l}0.152 \\
0.575\end{array}$ & 8 & & \\
\hline YP_FE_D (-1) & $\begin{array}{l}\text { Pearson Correlation } \\
\text { Sig. (2-tailed) }\end{array}$ & & $\begin{array}{l}0.070 \\
0.776\end{array}$ & & \\
\hline TV_FE_D (-1) & $\begin{array}{l}\text { Pearson Correlation } \\
\text { Sig. (2-tailed) }\end{array}$ & & & $\begin{array}{r}-0.478^{*} \\
0.045\end{array}$ & \\
\hline NA6_FE_D (-1) & $\begin{array}{l}\text { Pearson Correlation } \\
\text { Sig. (2-tailed) }\end{array}$ & & & & $\begin{array}{r}-0.010 \\
0.969 \\
\end{array}$ \\
\hline CR_FE_D & $\begin{array}{l}\text { Pearson Correlation } \\
\text { Sig. (2-tailed) }\end{array}$ & $\begin{array}{l}0.179 \\
0.492\end{array}$ & $\begin{array}{r}-0.049 \\
0.836 \\
\end{array}$ & $\begin{array}{l}0.090 \\
0.715\end{array}$ & $\begin{array}{r}-0.005 \\
0.983 \\
\end{array}$ \\
\hline CR_FE_D (-1) & $\begin{array}{l}\text { Pearson Correlation } \\
\text { Sig. (2-tailed) }\end{array}$ & $\begin{array}{l}0.478 \\
0.061 \\
\end{array}$ & $\begin{array}{r}-0.193 \\
0.428 \\
\end{array}$ & $\begin{array}{r}-0.296 \\
0.233 \\
\end{array}$ & $\begin{array}{l}0.191 \\
0.464\end{array}$ \\
\hline BR_FE_D & $\begin{array}{l}\text { Pearson Correlation } \\
\text { Sig. (2-tailed) }\end{array}$ & $\begin{array}{r}-0.219 \\
0.398 \\
\end{array}$ & $\begin{array}{l}0.112 \\
0.638 \\
\end{array}$ & $\begin{array}{l}0.147 \\
0.549 \\
\end{array}$ & $\begin{array}{r}-0.292 \\
0.239 \\
\end{array}$ \\
\hline BR_FE_D (-1) & $\begin{array}{l}\text { Pearson Correlation } \\
\text { Sig. (2-tailed) }\end{array}$ & $\begin{array}{l}0.445 \\
0.084\end{array}$ & $\begin{array}{r}-0.270 \\
0.263 \\
\end{array}$ & $\begin{array}{r}-0.547^{*} \\
0.019\end{array}$ & $\begin{array}{l}0.042 \\
0.873\end{array}$ \\
\hline FX_FE_D & $\begin{array}{l}\text { Pearson Correlation } \\
\text { Sig. (2-tailed) }\end{array}$ & $\begin{array}{r}-0.146 \\
0.575\end{array}$ & $\begin{array}{r}-0.104 \\
0.661\end{array}$ & $\begin{array}{r}-0.113 \\
0.647\end{array}$ & $\begin{array}{r}-0.430 \\
0.075\end{array}$ \\
\hline FX_FE_D (-1) & $\begin{array}{l}\text { Pearson Correlation } \\
\text { Sig. (2-tailed) }\end{array}$ & $\begin{array}{r}-0.116 \\
0.668\end{array}$ & $\begin{array}{l}0.030 \\
0.902\end{array}$ & $\begin{array}{r}-0.052 \\
0.839\end{array}$ & $\begin{array}{r}-0.033 \\
0.899\end{array}$ \\
\hline
\end{tabular}




\begin{tabular}{llrrrr}
\hline & & RMP_FE_D & YP_FE_D & TV_FE_D & NA6_FE_D \\
\hline ASX_FE_D & Pearson Correlation & -0.351 & 0.090 & 0.021 & -0.177 \\
& Sig. (2-tailed) & 0.167 & 0.705 & 0.932 & 0.483 \\
\hline ASX_FE_D (-1) & Pearson Correlation & $\mathbf{0 . 5 9 2}$ & $\mathbf{- 0 . 6 1 0 ^ { * * }}$ & $\mathbf{- 0 . 5 9 0 ^ { * * }}$ & 0.471 \\
& Sig. (2-tailed) & $\mathbf{0 . 0 1 6}$ & $\mathbf{0 . 0 0 6}$ & $\mathbf{0 . 0 1 0}$ & 0.057 \\
\hline
\end{tabular}

\section{CONCLUSIONS AND IMPLICATIONS}

The research paper critically presents the secondary data analysis, including testing of the Australian office market forecast accuracy, analysing outliers of forecast errors and testing for relationships for the period 2001-2011, including the GFC. The forecast accuracy measurement highlighted rental movement and net absorption forecast errors as the critical inaccurate predictions. Since naïve forecasting strategies out-performed the forecasters, the researchers suggest that the naive assumption must be incorporated as a key input variable in property forecasting. In this study, naive assumption is the last observed value in 6 months ago.

IQR analysis highlighted that the credibility of rental movement-prime (RMP) forecasts have been diminished by having extremely large errors given in percentage of actual. In particular, economists' forecasts have missed the GFC turning point; a significant man-made Black Swan economic event. Thus, forecasting uncertainty has become a more critical issue.

The conclusive evidence from the multiple regression analysis is that the key property variables have a strong coefficient correlation and an overall significance with independent economic variables and its own historic information. However, property forecast errors cannot be explained by economic forecast errors using multiple regression analysis. Furthermore, lagged values are considered under the VAR methodology to investigate any forward indicator for property forecast errors. As a key finding, there is a significant causality for all key property forecast errors by the lagged values of Australian S\&P/ASX 200 forecast errors. Moreover, there is a bi-directional causality of rental movements and total vacancy forecast errors with ASX that can be theoretically justified. Indirect investments are more liquid, tradable and transparent assets; therefore they adjust to market dynamics much faster. This seems to be a forward indicator for the direct property market. There has been a disconnect between property forecast fundamentals, and the property market tends to follow the broader capital market in terms of listed market performance.

The study has revealed property forecast errors deviate significantly from economic forecast errors across the period of concern without any explainationexplanation from mainstream economics.a wider spread in between property forecast errors and economic forecast errors. Property forecasting Hence, forces beyond economic factoring, $\underline{s}$ needs to be integrated in property forecast modelling. Apart from the effects of the GFC, this quantitative study is lacking the identification of causal factors for property forecast errors. Therefore, further research will use a qualitative approach to ascertain the Known, unknown and Unknowable (KuU) risk factors in commercial property market for further improvement of property forecasts. 


\section{REFERENCES}

Armstrong, J. S. (2001). Principles of Forecasting A Handbook for Researchers and Practitioners, Springer Science+Business Media, LLC, New York.

Ball, M., Lizieri, C., \& MacGregor, B. D. (1998). The Economics of Commercial Property Markets, Routledge, London.

Bardhan, A., \& Edelstein, R. H. (2010). Real estate through the ages: The known, the unknown, and the unknowable. In X. D. Francis, A. D. Neil, \& J. H. Richard (Eds.), The Known, the Unknown, and the Unknowable in Financial Risk Management: Measurement and Theory Advancing Practice, Princeton, Princeton University Press, pp. 145-163.

Brooks, C., \& Tsolacos, S. (2000). 'Forecasting models of retail rents'. Environment \& Planning $A$, Vol. 32 (10), pp. 1825.

Brooks, C., \& Tsolacos, S. (2001). 'Forecasting real estate returns using financial spreads'. Journal of Property Research, Vol. 18 (3), pp. 235-248.

Brooks, C., \& Tsolacos, S. (2003). 'International evidence on the predictability of returns to securitized real estate assets: econometric models versus neural networks'. Journal of Property Research, Vol. 20 (2), pp. 133-155.

Brooks, C., \& Tsolacos, S. (2010). Real Estate Modelling and Forecasting (3 edn ed.), Cambridge University Press, Cambridge, UK.

Carnot, N., Koen, V., \& Tissot, B. (2005). Economic Forecasting, Palgrave Macmillan, New York.

Chaplin, R. (1998). 'An ex post comparative evaluation of office rent prediction models'. Journal of Property Valuation \& Investment, Vol. 16 (1), pp. 21-37.

Chaplin, R. (1999). 'The predictability of real office rents'. Journal of Property Research, Vol. 16 (1), pp. 21-49.

Chaplin, R. (2000). 'Predicting real estate rents: walking backwards into the future'. Journal of Property Investment \& Finance, Vol. 18 (3), pp. 352-370.

D'Arcy, E., McGough, T., \& Tsolacos, S. (1999). 'An econometric analysis and forecasts of the office rental cycle in the Dublin area'. Journal of Property Research, Vol. 16 (4), pp. 309-321.

Gell, S. (2012). Determinants of Earnings Forecast Error, Earnings Forecast Revision and Earnings Forecast Accuracy, Springer, Dordrecht.

Geltner, D., \& De Neufville, R. (2015). 'Uncertainty, flexibility, valuation and design: How 21 st century information and knowledge can improve 21st century urban development - Part II of II'. Pacific Rim Property Research Journal, Vol. 18 (3), pp. 251-276.

Granger, C. W. (1969). 'Investigating causal relations by econometric models and cross-spectral methods'. Econometrica: Journal of the Econometric Society, Vol., pp. 424-438.

Gujarati, D. N., \& Porter, D. C. (2009). Basic Econometrics (5th ed. ed.), McGraw-Hill Irwin, Boston.

Higgins, D. (2000). The determinants of commercial property market performance.

Hyndman, R. J. (2006). 'Another look at forecast-accuracy metrics for intermittent demand'. Foresight: The International Journal of Applied Forecasting, Vol. 4 (4), pp. 43-46.

JLL. (2016). Global Real Estate Transparency Index: JLL.

Karakozova, O. (2004). 'Modelling and forecasting office returns in the Helsinki area'. Journal of Property Research, Vol. 21 (1), pp. 51-73.

Makridakis, S., Hogarth, R. M., \& Gaba, A. (2009). 'Forecasting and uncertainty in the economic and business world'. International Journal of Forecasting, Vol. 25 (4), pp. 794-812.

Matysiak, G., Papastamos, D., \& Stevenson, S. (2012). Reassessing the Accuracy of UK Commercial Property Forecasts: IPF Research Programme.

Matysiak, G., \& Tsolacos, S. (2003). 'Identifying short-term leading indicators for real estate rental performance'. Journal of Property Investment \& Finance, Vol. 21 (3), pp. 212232. 
McGough, T., Tsolacos, S., \& Olli, O. (2000). 'The predictability of office property returns in Helsinki'. Journal of Property Investment \& Finance, Vol. 18 (6), pp. 565-585.

McMahan, J. (2006). The Handbook of Commercial Real Estate Investing, McGraw-Hill, New York.

Newell, G., \& MacFarlane, J. (2006). 'The accuracy of commercial property forecasting in Australia'. Pacific Rim Property Research Journal, Vol. 12 (3), pp. 311-325.

Stevenson, S., \& McGarth, O. (2003). 'A comparison of alternative rental forecasting models: empirical tests on the London office market'. Journal of Property Research, Vol. 20 (3), pp. 235-260. 


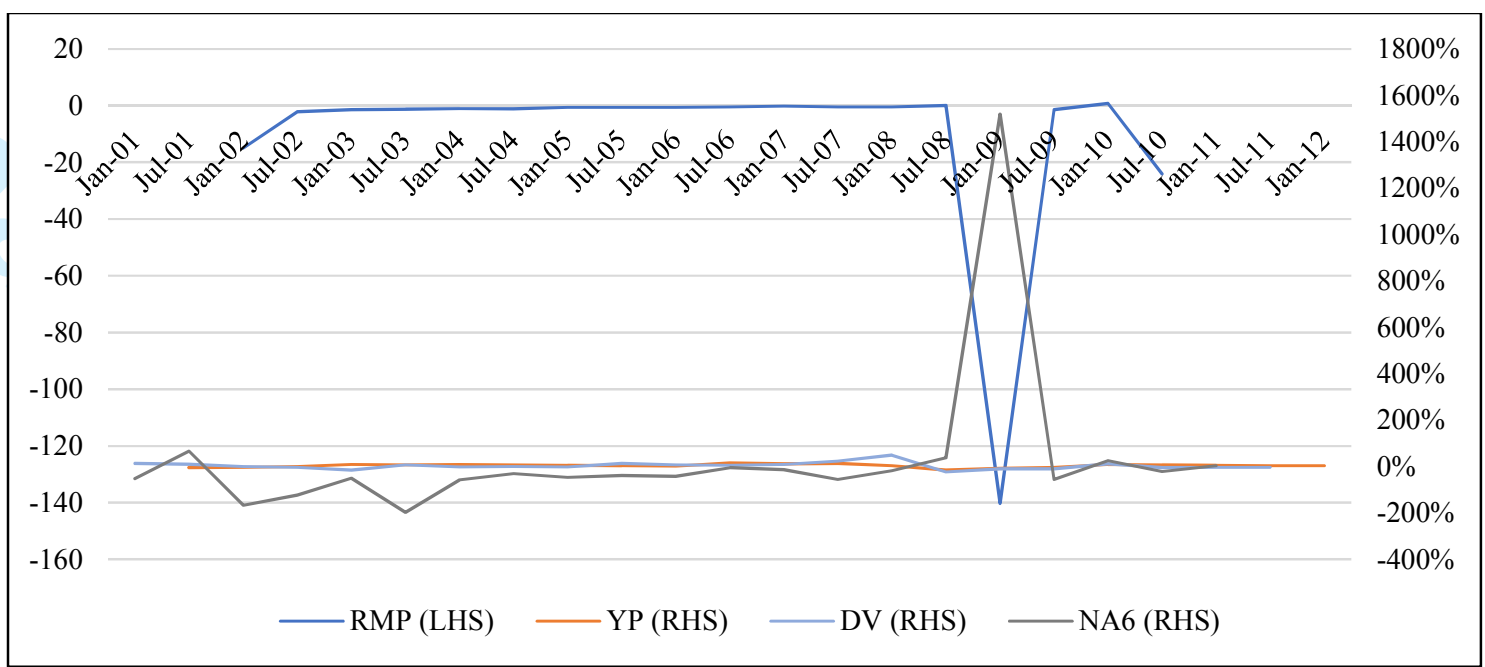

Figure 2: Line Diagram for Property Forecasts Errors in Percentages

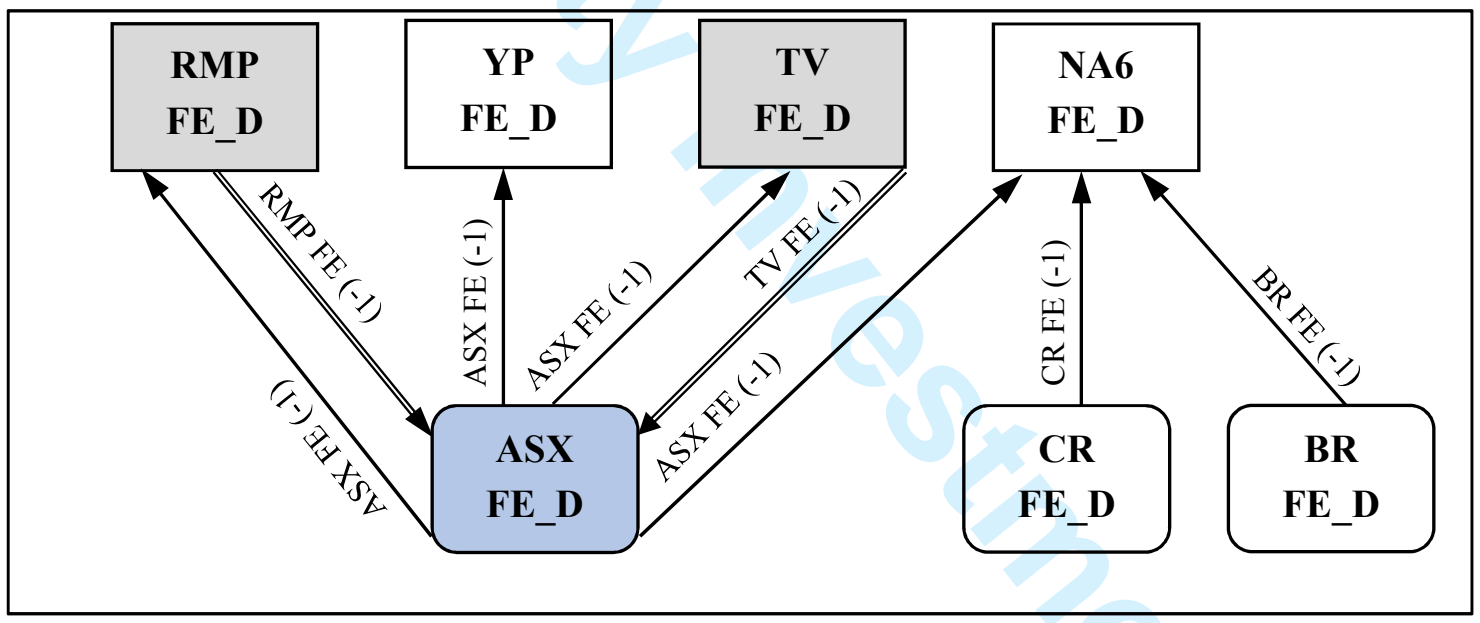

Figure 3: Granger Causality of Property and Economic Forecast Errors 